\title{
NUEVOS DATOS DE LA OCUPACIÓN HUMANA EN LA TRANSICIÓN BOSQUE ESTEPA EN PATAGONIA: ALERO LAS QUEMAS (COMUNA DE LAGO VERDE, XI REGIÓN DE AISÉN).
}

\author{
CÉSAR MÉNDEZ M.* y OMAR REYES B.*
}

\begin{abstract}
RESUMEN
Se presenta la caracterización del material lítico proveniente del sitio alero Las Quemas (valle del río Cisnes, Región de Aisén 44은), además de la primera datación radiocarbónica. Ubicado en la transición bosque-estepa, se trata de un alero con pinturas rupestres excavado en 1996 por Francisco Mena, y cuyos materiales han sido retomados en el contexto de una discusión mayor; la dispersión y ocupación de diferentes ambientes (bosque siempre verde, bosque caducifolio y estepa) por parte de grupos cazadores recolectores esteparios en Patagonia Central.
\end{abstract}

PALABRAS CLAVE: poblamiento, transición bosque-estepa, lítico, Patagonia central.

NEW INFORMATION ON HUMAN SETTLEMENT IN THE FOREST STEPPE TRANSITION IN PATAGONIA: LAS QUEMAS ROCKSHELTER (LAGO VERDE DISTRICT, XI REGIÓN OF AISÉN).

\section{ABSTRACT}

This article refers to the characterization of Las Quemas site lithic assemblage (Cisnes river valley, Aisén region, $440 \mathrm{~S}$ ) and its first radiocarbon date. This site is a cave with rock art, located in the forest-steppe transition and was first excavated in 1996 by Francisco Mena. The materials have been approached in the context of a greater discussion related to the dispersion and occupation of different environments (evergreen woods, deciduous forest and steppe) by steppe hunter gatherers in central Patagonia.

KEY WORDS: peopling, forest steppe transition, lithic, central Patagonia.

* Departamento de Antropología, Facultad de Ciencias Sociales, Universidad de Chile. Ignacio Carrera Pinto 1045, Ñuñoa, Santiago. cmendezm@uchile.cl.

** Centro de Estudios del H ombre Austral, Instituto de la Patagonia, Universidad de Magallanes. Avda. Bulnes 1890, Punta Arenas. 
Desde hace algunos años existe un creciente interés en la arqueología de Patagonia por documentar áreas que se han mantenido marginales al conocimiento. Probablemente ha influido, su desocupación al momento de la colonización republicana (p.e. Goñi 2000, Mena y Lucero 2004), el pobre reflejo etnográfico en algunas zonas (etnias desconocidas o no documentadas), su difícil accesibilidad o bien la lejanía de los actuales centros más poblados, o incluso una mezcla de las variables antes mencionadas (Velásquez 2002). Esto es particularmente sintomático en las zonas boscosas, donde debemos sumar la dificultad que tenemos los arqueólogos en dar cuenta de la presencia humana en vistas de las restricciones de visibilidad. En un esfuerzo por iniciar un camino que nos permitiera comparar áreas marginalmente conocidas con espacios con alta intensidad de uso, llevamos a cabo nuevos análisis en contextos previamente identificados y excavados por Francisco Mena en distintos segmentos del valle del río Cisnes. Estos análisis contemplan el estudio de los materiales recuperados y la obtención de dataciones radiocarbónicas que nos permitan establecer secuencias cronológicas de las mencionadas ocupaciones. Uno de los sitios trabajados ha sido Alero El Toro, a través del cual se pudo establecer una presencia humana de cierta intensidad inserta en el bosque siempreverde ( $30 \mathrm{~km}$ de la costa del Pacífico) durante el lapso de 2740 y 2400 años cal. AP (Méndez et al. 2006). El segundo yacimiento que nos propusimos trabajar es el reportado en este trabajo: alero Las Quemas. El sitio se ubica en el curso medio del río Cisnes (Fig. 1), a 750 msnm en un imponente reparo rocoso cuya cima es cercana a los 940 msnm. Dado que el sitio fue trabajado previamente por $F$. Mena, todas las referencias generales aquí señaladas provienen de su reporte original (Mena 1996); el investigador, gentilmente nos facilitó las muestras y permitió trabajar con los materiales. El alero tiene una longitud de $35 \mathrm{~m}$ con un área de protección de $\sim 150 \mathrm{~m}^{2}$ y se encuentra directamente adyacente a una planicie que lo vincula al arroyo homónimo. Bajo el área de reparo se excavó un sondeo
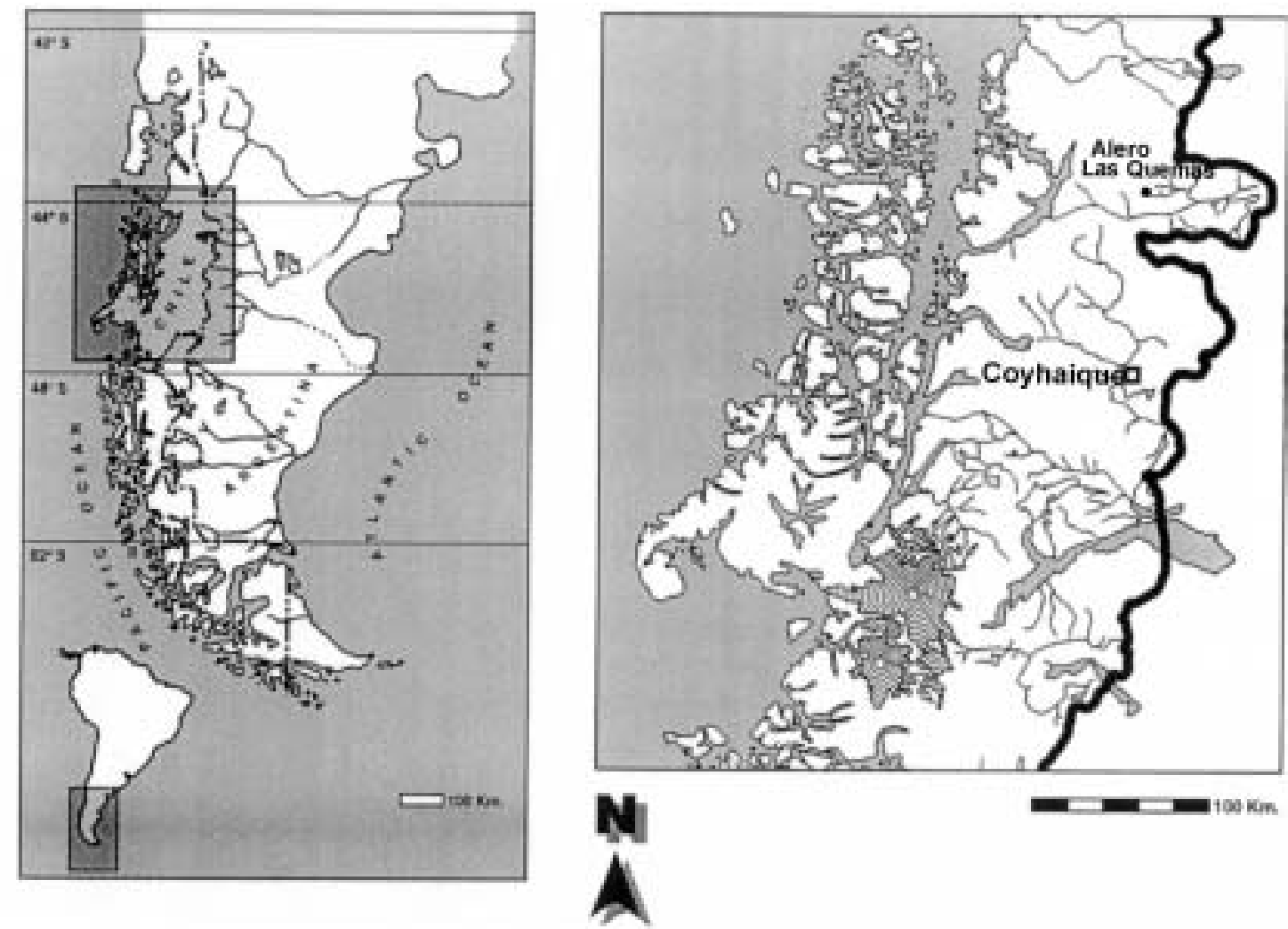

Fig. 1. Ubicación del Alero Las Quemas y su contexto regional. 
inicial $\left(1 \mathrm{~m}^{2}\right)$ a fin de caracterizar sus depósitos. De esta actividad se registró escaso material lítico y algunas espículas de carbón en sus 3 capas registradas. Su característica principal no obstante, y aquella que motivó su reporte inicial, fue la presencia de pinturas rupestres con motivos geométricos simples y extensas superficies con pintura roja que se atribuyen a una profusión de motivos (posiblemente conjuntos de manos), hoy deslavados. Entre los motivos inteligibles se observan círculos concéntricos, composiciones lineales simples, demarcación de fisuras en las rocas, arrastre de dedos, tridígitos (¿huellas de ñandú?) y una roseta (¿huella de puma?), esta última integra técnicas de picoteo y pintura. En vistas de los motivos representados, el autor consideró una cronología relativa en el lapso entre los 3000 AC y 800 DC, consecuente con las similitudes al grupo estilítico Illa del río Pinturas (Mena 1996). Las únicas otras referencias de arte rupestre en la zona provienen de bardas distantes $2 \mathrm{~km}$ del actual pueblo Lago Verde (sitios 1 y 2 ) y corresponden a manos en positivo y trazos lineales simples en pintura roja (Reyes 2003).

F. Mena (1996) destacó al sitio en su calidad de refugio como una ruta obligada de paso entre sectores boscosos y las estepas, considerando su buena visibilidad y características de reparo, en lo que habrían sido visitas residenciales restringidas o bien estadías logísticas. Comparándolo con las ocupaciones más meridionales, acentuó las diferencias con áreas de mayor intensidad de ocupación (p.e. río lbáñez) en donde incluso las áreas boscosas evidenciaban mayor presencia humana (p.e. alero Fontana, Mena 1992).

Consecuente con el lapso sugerido por Mena, la edad radiocarbónica AMS sobre carbón obtenida en el alero Las Quemas fue de 2510 \pm 40 años AP (Beta 214640, 2': 2740 a 2450 años cal. AP y 2410 a 2380 años cal. AP, 13C/ 12C: - 26.0 o/00, unidad única, capa 3). Esta asignación cronológica nos permite tener una referencia mínima para la ocupación del segmento medio del río Cisnes y los materiales arqueológicos depositados en el contexto. Así también, destacamos que el lapso calendárico de Las Quemas -2740 a 2380 años cal. AP-, coincide significativamente con las dataciones iniciales obtenidas en el mismo valle en los sectores de estepa (alero EI Chueco, CIS 042) -2730 a 2360 años cal. AP. (Reyes et al. 2006)- y cercanos a la desembocadura en el bosque siempreverde (ale-

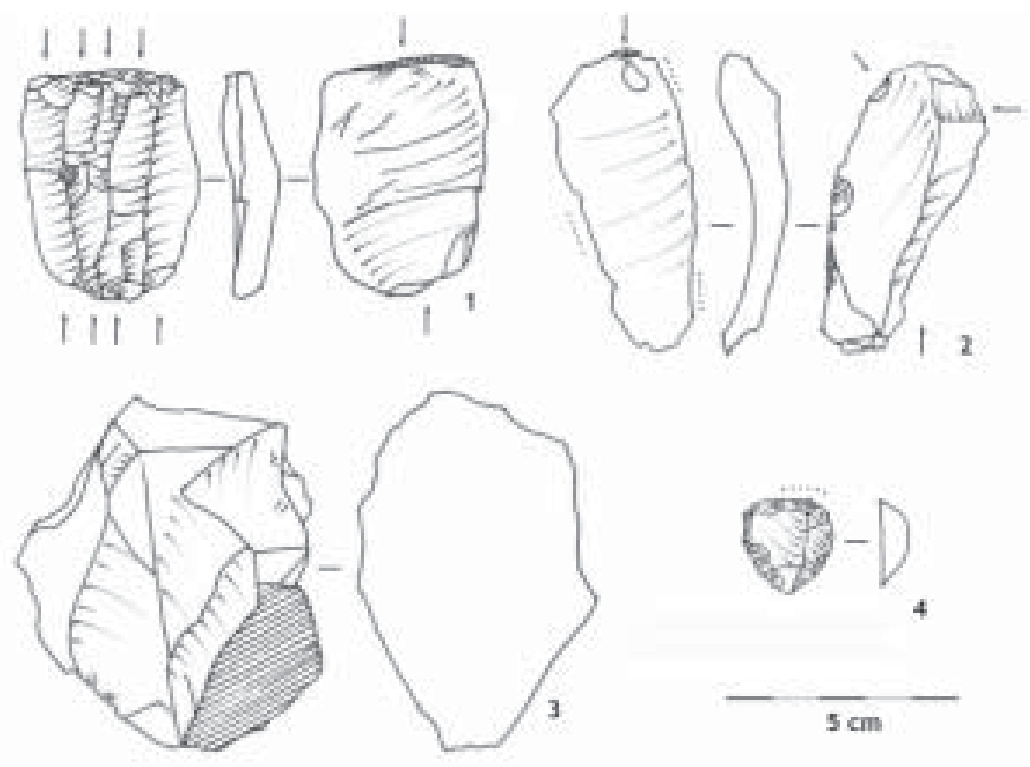

Fig. 2. Material lítico de alero Las Quemas, unidad única: 1. derivado de núcleo bipolar (capa 1, base), 2. lámina usada para raído en sílice verde (capa 2, techo, cuadrante SE), 3. núcleo multidireccional en roca tobácea (capa 2, techo, cuadrante NW), 4. raspador "en uña" en sílice blanca semi-translúcida (capa 3). Flechas: dirección del astillamiento, líneas punteadas: micropulido por uso. 
ro El Toro) 2740 y 2400 años cal. AP (Méndez et al. 2006). El significado de dicha contemporaneidad en distintos ambientes será evaluado en próximas etapas de la investigación arqueológica del valle del río Cisnes.

CARACTERIZACIÓN DEL MATERIAL LÍTICO DE ALERO LAS QUEMAS

\section{Capa 1:}

Se registró un derivado de un núcleo bipolar (Fig. 2.1) con remanentes de múltiples extracciones anteriores en su anverso. Éstas, sin excepción, son laminares y paralelas al eje tecnológico de la pieza, demostrando un patrón de talla anterior desde dos plataformas opuestas. Un golpe final, con el uso de un yunque en la base, produjo la extracción de la lasca que muestra dos direcciones de ondas que convergen antes de la mitad inferior de la pieza (característica de talla bipolar). El golpe con percutor móvil fue realizado sobre una plataforma natural. La materia prima es de difícil asignación puesto que posee una pátina muy intensa que sugiere larga exposición, posiblemente antes del traslado hacia el reparo rocoso. Asimismo se observó una pequeña lasca de sílice blanca traslúcida y un fragmento distal de lasca de sílice verde.

\section{Capa 2:}

Se registró una lámina (Fig. 2.2) de sílice verde de alta calidad con microastillamiento por uso en ambos márgenes y pulimento en sectores restringidos sobre la cara ventral. Dadas estas características y su morfología curva se piensa que se utilizó para labores de raído, cuyo deslizamiento pudo generar las trazas. Proviene de un núcleo multidireccional como se puede apreciar en los astillamientos anteriores en su anverso, aunque probablemente éstas fueron extracciones de formatización del mismo. La lámina en sí, dada su morfología y talón facetado, parece ser de primera serie. Posee escasos remanentes de corteza y dos a tres pequeños golpes marginales (astillamiento) en un borde útil. No hay que descartar evidencias de exposición al fuego de la pieza.

En esta unidad litológica se identificó también un núcleo multidireccional (Fig. 2.3) sobre una materia prima tobácea silicificada de color verde y calidad media a buena. No se observó sistemática de talla definida entre las extraccio- nes de percusión dura directa. Posee escaso remanente de corteza y múltiples clivajes que produjeron cortes en bisagra. Ambas piezas destacadas, se encuentran asociadas a dos derivados de núcleo, uno sobre una sílice blanca traslúcida y otro en andesita.

\section{Capa 3:}

En la capa basal se observó un raspador "en uña" (pequeño, frontal, enmangable, Fig. 2.4) en sílice blanca semi-translúcida. Se encuentra manufacturado sobre una lasca cuyo talón ha sido removido. Se observa astillamiento y regularización en gran parte de su contorno. Análisis funcionales confirman presencia de microastillamiento en todo el contorno y pulimento en un segmento restringido, por lo que se sugiere que la pieza probablemente se rotó al agotar sus filos. Acompañan en este nivel dos lascas de una posible toba silicificada muy oscura. Una es un derivado de núcleo pequeño (talón plano) y la otra es una posible cuña. A demás se observó un derivado de núcleo de una roca de granulometría muy gruesa (talón plano) y tres subproductos de talla en una roca tobácea silicificada verde que corresponde a la misma variedad del núcleo de la capa 2. No fue posible reensamblar las piezas, aunque no se descarta que excavaciones ampliadas permitirán entender la secuencia de desbaste de dicho núcleo y sus lascas.

\section{COMENTARIOS}

Las excavaciones conducidas previamente, pese a ser bastante restringidas, han permitido datar y analizar un contexto en un área previamente inexplorada. Han mostraron una interesante variabilidad de recursos líticos, cuya proveniencia deberá ser evaluada en campañas venideras. Esta característica deberá ser revisada a la luz de la calidad de "paso" del sector, anteriormente sugerida por F. Mena (1996). Algunos elementos tecnológicos y estilísticos permiten resaltar la discusión de los posibles vínculos con otras áreas en la región, y de ahí el tema de la movilidad a lo largo de estos parajes. Por ejemplo, la presencia de un raspador en uña y tecnología de láminas son elementos propios de Patagonia Central durante el Holoceno tardío, y poseen una significativa representación en sitios residenciales del sector estepario de valle del Cisnes (Méndez 2006). Situación similar ocurre con 
la presencia de motivos rupestres recurrentes, tanto en las estepas, como otros bosques andinos orientales (p.e. cuenca del río lbáñez) en la región de Aisén. Destacamos, no obstante, la presencia de técnica bipolar, elemento muy poco común en esta área de Patagonia. Incluso, es sintomático que nada parecido se haya registrado ni en la estepa (Méndez 2006), ni en el bosque siempreverde (Méndez et al. 2006). La presencia de técnica bipolar puede ser observada como una solución tecnológica disponible en el repertorio de los cazadores recolectores, aunque deberá discutirse su representación y eventuales motivaciones.

Las labores programadas a futuro en la zona contemplan la ampliación de las excavaciones en el alero y el desarrollo de prospecciones sistemáticas en el sector medio del río Cisnes (Tapera). Estas tareas permitirán ampliar este panorama inicial exploratorio. Así mismo, la etapa de investigación de este sector medio del valle, responde a la intención más ambiciosa de evaluar el tránsito humano por sectores cuyas características geográficas habrían consentido el flujo de poblaciones entre la estepa y la costa, como es el particular caso del valle del río Cisnes. En dicho sentido, nuestro trabajo pretende aportar y comunicar datos relativos a un problema arqueológico que se encuentra recién conociéndose.

\section{AGRADECIMIENTOS}

Esta investigación fue financiada por CONICYT a través de su proyecto FONDECYT 1050139. Compromete nuestra gratitud Francisco Mena quien nos dio to das las facilidades para trabajar conjuntos de yacimientos originalmente trabajados por él.

\section{BIBLIOGRAFÍA}

GOÑI, R. 2000 Arqueología de momentos históricos fuera de los centros de conquista y colonización: un análisis de caso en el sur de la Patagonia. En: Desde el país de los gigantes. Perspectivas arqueológicas en Patagonia. Universidad de Nacional de la Patagonia Austral. Tomo I: 283-296, Río Gallegos.

MENA, F. 1992 Mandíbulas y maxilares: un primer acercamiento a los conjuntos arqueofaunísticos del Alero Fontana (RI-22; XI Región). Boletín del Museo Nacional de Historia Natural 43:179-191.

MENA, F. 1996 Alero Las Quemas: Un sitio arqueológico en las montañas del Alto Río Cisnes. Informe a la I. Municipalidad Lago Verde, Proyecto FONDART 1016/1996. Santiago, 14 pp. MS.

MENA, F. y V. LUCERO. 2004 En torno a las últimas poblaciones indígenas de la cordillera centro-patagónica: estudio comparado de tres valles en Aisén oriental (Chile). En: Actas de las V J ornadas de Arqueología de la Patagonia, editado por M. Civalero, P. Fernández y G. Guráieb, pp. 643-657. Buenos Aires.

MÉNDEZ, C. 2006 Tecnología lítica, función de sitio y adscripción crono-cultural de asentamientos de cazadores recolectores esteparios en Alto río Cisnes (IX Región de Aisén). Análisis de material lítico de la campaña 2005. En: Proyecto FONDECYT 1050139 - Año 1, compilado por O. Reyes, H. Velásquez y C. Méndez, 39 pp. Santiago. MS.

MÉNDEZ, C., H. VELASQUEZ, O. REYES y V. TREJ O. 2006 Tras los moradores del bosque. Análisis de los conjuntos arqueológicos de Alero EI Toro (Valle del río Cisnes, Región de Aisén). Werken 8, en prensa.

REYES, 0. 2003 Evaluación de los sitios arqueológicos descubiertos en los sectores de Planicie y Semillero, curso superior valle de Lago Verde, cuenca hidrográfica del río Palena. Región de Aisén. Informe a la I. Municipalidad Lago Verde, Santiago, 12 pp. MS.

REYES, O., C. MÉNDEZ, H. VELÁSQUEZ y V. TREJ O. 2006. Distribuciones espaciales y contextos arqueológicos de cazadores recolectores esteparios en Alto río Cisnes (XI Región de Aisén). Magallania, en evaluación.

VELÁSQUEZ, H. 2002 En busca de aportes documentales al conocimiento de la realidad sociocultural del actual territorio oriental de Aisén en la transición siglo XIX- siglo XX. Anales del Instituto de la Patagonia, Serie Ciencias Humanas 30:45-64. 